\title{
Calculated Tumor Volume Is an Independent Predictor of Biochemical Recurrence in Patients Who Underwent Retropubic Radical Prostatectomy
}

\author{
Nobumichi Tanaka, ${ }^{1}$ Kiyohide Fujimoto, ${ }^{1}$ Akihide Hirayama, ${ }^{1}$ \\ Yasushi Nakai, ${ }^{1}$ Yoshitomo Chihara, ${ }^{1}$ Satoshi Anai, ${ }^{1}$ Atsushi Tomioka, ${ }^{2}$ \\ Keiji Shimada, ${ }^{3}$ Noboru Konishi, ${ }^{3}$ and Yoshihiko Hirao ${ }^{1}$ \\ ${ }^{1}$ Department of Urology, Nara Medical University, 840 Shijo-cho, Kashihara, Nara 634-8522, Japan \\ ${ }^{2}$ Nara Uro-Oncological Research Group, Kashihara, Japan \\ ${ }^{3}$ Department of Pathology, Nara Medical University, Nara 634-8522, Japan
}

Correspondence should be addressed to Nobumichi Tanaka, sendo@naramed-u.ac.jp

Received 15 November 2011; Revised 23 February 2012; Accepted 5 March 2012

Academic Editor: A. Stenzl

Copyright (C) 2012 Nobumichi Tanaka et al. This is an open access article distributed under the Creative Commons Attribution License, which permits unrestricted use, distribution, and reproduction in any medium, provided the original work is properly cited.

\begin{abstract}
Purpose. The purpose of this study is to investigate whether the clinicopathological biopsy findings can predict the oncological outcome in patients who undergo radical prostatectomy. Materials and Methods. Between January 1997 and March 2006,255 patients with clinically localized adenocarcinoma of the prostate (clinical T1-3N0M0) who had undergone retropubic radical prostatectomy were enrolled in this study. None of the patients received neoadjuvant or adjuvant therapy. Clinicopathological parameters were assessed to determine a predictive parameter of biochemical recurrence. Results. Of the total 255 patients, 77 showed biochemical recurrence during the follow-up period. The estimated 5-year overall survival, 5-year cause-specific survival, and 5-year biochemical recurrence-free survival rates were $97.7 \%, 99.5 \%$, and $67.3 \%$, respectively. Multivariate analysis using the Cox proportional hazards model showed that calculated cancer volume was an independent predictor among the preoperative clinicopathological parameters $(P<0.05)$. SVI and PSM were independent predictors among the postoperative parameters (SVI; $P<0.001$, PSM; $P=0.049)$. Among the significant preoperative and postoperative parameters, calculated cancer volume remained an independent predictive parameter in multivariate analysis $(P<0.01)$. Conclusions. Tumor volume, as calculated by preoperative parameters, is an independent predictor of biochemical recurrence in patients who had undergone radical prostatectomy.
\end{abstract}

\section{Introduction}

Radical prostatectomy has been the gold standard of definitive therapy for patients with localized prostate cancer for years [1]. Now, not only laparoscopic radical prostatectomy, but recently also robotic radical prostatectomy has remained popular over the years all across the world $[2,3]$.

Prostate cancer patients have been able to choose their primary treatment modality among several treatment options since the technical development of radiation therapy such as 3-dimensional conformal radiation therapy (3DCRT), intensity modulated radiation therapy (IMRT), lowdose-rate brachytherapy (LDR-brachytherapy), and highdose-rate brachytherapy (HDR-brachytherapy) [4]. If it is possible to predict the oncological outcome based on the clinicopathological findings at diagnosis, it will be possible to choose the most suitable treatment option in patients who receive definitive therapy.

The purpose of this study is to investigate whether the clinicopathological biopsy findings can predict the oncological outcome in patients who are undergoing radical prostatectomy.

\section{Material and Methods}

Between January 1997 and March 2006, there were 577 patients who consecutively underwent retropubic radical 
prostatectomy at Nara Medical University Hospital and its affiliate hospitals. Among all of these patients, 255 patients who did not receive neoadjuvant or adjuvant therapy and had clinically localized adenocarcinoma of the prostate (clinical T1-3N0M0; 2002 UICC classification [5]) were enrolled in this retrospective study. The mean follow-up period was 53 months (range: 12-127 months). The mean age at surgery and PSA value at diagnosis were 67.4 years and $10.9 \mathrm{ng} / \mathrm{mL}$, respectively.

Patients' course was followed every 3 to 6 months until 5 years after surgery, and then every 6-12 months thereafter. At each visit, PSA was measured and digital rectal examination was performed. If clinical recurrence was suspected, patients underwent a bone scan, computed tomography, and magnetic resonance examination. Biochemical recurrence was defined as a PSA value of $0.2 \mathrm{ng} / \mathrm{mL}$ or greater.

Regarding preoperative clinicopathological findings, age at surgery, PSA at diagnosis, biopsy Gleason score, clinical $\mathrm{T}$ stage, percent positive biopsy cores, risk classification by D'Amico et al. [6], and calculated cancer volume reported by D'Amico et al. [7] were used to predict biochemical recurrence. Patients were stratified by PSA level at diagnosis of $10 \mathrm{ng} / \mathrm{mL}$ or less, greater than $10 \mathrm{ng} / \mathrm{mL}$ to $20 \mathrm{ng} / \mathrm{mL}$ or less, and greater than $20 \mathrm{ng} / \mathrm{mL}$, respectively, by Gleason score (biopsy and surgical) of 6 or less, 7 and 8-10, respectively. Patients were stratified by a volume of $2.0 \mathrm{~mL}$ or less, greater than $2.0 \mathrm{~mL}$ to $4.0 \mathrm{~mL}$ or less, and greater than $4.0 \mathrm{~mL}$, respectively. Patients were also stratified by positive biopsy core of less than $34 \%, 34 \%$ or greater but less than $50 \%$, and $50 \%$ or greater, respectively, and D'Amico risk classification [6] was used for risk classification. Regarding postoperative pathological findings, pathological $\mathrm{T}$ stage, extraprostatic extension (EPE), seminal vesicle involvement (SVI), positive surgical margin (PSM), and surgical Gleason score were examined in the same manner.

Biochemical recurrence-free rate was calculated by the Kaplan-Meier method. Comparison of the biochemical recurrence-free rate stratified by clinicopathological parameters was tested by the log rank test. The Cox proportional hazards model was used to determine the predictive parameter of biochemical recurrence among the preoperative and the postoperative parameters both in univariate and multivariate analyses. Finally, the Cox proportional hazards model was used to determine the predictive parameter using the significant predictive parameters among the preoperative and postoperative parameters in multivariate analysis. To examine differences in categorical parameters, the chi-square test was used. Mann-Whitney $U$ test was used to examine differences in continuous variables. All $P$ values below 0.05 were considered to be statistically significant.

The institutional reviewer board approved this retrospective study, and the obtainment of informed consent from the patients was exempted in view of the aim and methods of this study.

\section{Results}

Of the total 255 patients, 77 showed biochemical recurrence during the follow-up period. Of these 77 patients, 2 patients showed clinical recurrence, and 63 patients underwent salvage therapy (44 patients: androgen deprivation therapy, 11 patients: radiotherapy, and 8 patients: both androgen deprivation therapy and radiotherapy), while 14 patients took a wait-and-see approach after biochemical recurrence. The estimated 5-year overall survival, cause-specific survival and biochemical recurrence-free survival rates were $97.7 \%$, $99.5 \%$, and $67.3 \%$, respectively. The estimated 10 -year overall survival, cause-specific survival, and biochemical recurrence-free survival rates were $80.2 \%, 99.5 \%$, and $56.2 \%$, respectively. Patients' demographics are listed in Tables 1 and 2. PSA level at diagnosis, biopsy Gleason score, clinical $T$ stage, calculated cancer volume, percent positive biopsy core and risk classification were statistically higher in patients who showed biochemical recurrence than in those who did not show biochemical recurrence.

\subsection{Biochemical Recurrence-Free Rate of Preoperative Clin-} icopathological Parameters. Regarding the clinical T stage, the estimated 5-year biochemical recurrence-free rates of T1a-b, T1c, T2, and T3a were $80.0 \%, 74 \%, 57 \%$, and $51 \%$, respectively. There was a significant difference between T1c and $\mathrm{T} 2$ stage $(P=0.0379)$.

Stratified by the biopsy Gleason score, the estimated 5year biochemical recurrence-free rates of a Gleason score of 6 or less, 7, and $8-10$ were $76.2 \%, 68.2 \%$, and $24.4 \%$, respectively. Patients with a Gleason score of 6 or less showed a significant higher biochemical recurrence-free rate than those with a Gleason score of 7 and $8-10$, respectively $(P=$ 0.0377 and $P<0.001)$. There was a significant biochemical recurrence-free rate difference between Gleason score 7 and $8-10(P=0.0159)$.

The estimated 5-year biochemical recurrence-free rates of patients with a PSA level at diagnosis of $10 \mathrm{ng} / \mathrm{mL}$ or less, $10.1-20 \mathrm{ng} / \mathrm{mL}$, and greater than $20 \mathrm{ng} / \mathrm{mL}$ were $74.4 \%$, $65.7 \%$, and $23.3 \%$, respectively. There were significant differences between the $10 \mathrm{ng} / \mathrm{mL}$ or less and the greater than $20 \mathrm{ng} / \mathrm{mL}$ groups, and between the $10.1-20 \mathrm{ng} / \mathrm{mL}$ and the greater than $20 \mathrm{ng} / \mathrm{mL}$ groups, respectively $(P<0.0001$ and $P=0.0002$ ).

Stratified by the percent positive core, the estimated 5 -year biochemical recurrence-free rates of patients with less than $34 \%, 34 \%$ to less than $50 \%$ and $50 \%$ or greater were $75.3 \%, 55.0 \%$, and $45.1 \%$, respectively. There were significant differences between patients with less than $34 \%$ and those with $50 \%$ or greater $(P<0.0001)$.

Risk classification also showed a significant difference in the biochemical recurrence-free rate. The estimated 5-year biochemical recurrence-free rates of patients with a low risk, an intermediate risk, and a high risk were $79.0 \%, 71.9 \%$ and $48.8 \%$, respectively. The high-risk patient group showed a significantly higher biochemical recurrence rate compared with the low- and intermediate-risk patient groups $(P=$ 0.0004 and 0.0375 ).

Stratified by calculated cancer volume, the estimated 5 -year biochemical recurrence-free rates of patients with $2.0 \mathrm{~mL}$ or less, $2.1-4.0 \mathrm{~mL}$, and greater than $4.0 \mathrm{~mL}$ were $81.1 \%, 51.0 \%$, and $12.0 \%$, respectively. Patients with $2.0 \mathrm{~mL}$ 
TABle 1: Preoperative clinicopathological parameters.

\begin{tabular}{|c|c|c|c|c|}
\hline & $\begin{array}{l}\text { All patients } \\
(n=255)\end{array}$ & $\begin{array}{c}\text { Biochem. recur. }(+) \\
\quad(n=77)\end{array}$ & $\begin{array}{l}\text { Biochem. recur. }(-) \\
\quad(n=178)\end{array}$ & $P$ value \\
\hline Age & $67.4 \pm 5.8$ & $67.1 \pm 5.4$ & $67.6 \pm 5.9$ & n.s. ${ }^{\S}$ \\
\hline \multicolumn{5}{|l|}{$\begin{array}{l}\text { PSA at biopsy } \\
(\mathrm{ng} / \mathrm{mL})\end{array}$} \\
\hline Mean \pm SD & $10.9 \pm 7.2$ & $14.1 \pm 9.9$ & $9.6 \pm 5.2$ & $<0.001^{\S}$ \\
\hline 10 or less & 151 & 35 & 116 & \\
\hline $10-20$ & 84 & 28 & 56 & \\
\hline Greater than 20 & 20 & 14 & 6 & $<0.001^{*}$ \\
\hline \multicolumn{5}{|l|}{ Biopsy Gleason score } \\
\hline 6 or less & 144 & 32 & 112 & \\
\hline 7 & 63 & 20 & 43 & \\
\hline $8-10$ & 25 & 9 & 16 & \\
\hline Unknown & 23 & 9 & 14 & $<0.001^{*}$ \\
\hline \multicolumn{5}{|l|}{ Clinical stage } \\
\hline $\mathrm{T} 1$ & 151 & 38 & 113 & \\
\hline T2 & 102 & 38 & 64 & \\
\hline $\mathrm{T} 3$ & 2 & 1 & 1 & $0.001^{*}$ \\
\hline \multicolumn{5}{|l|}{$\begin{array}{l}\text { Calculated cancer } \\
\text { volume }(\mathrm{mL})\end{array}$} \\
\hline 2.0 or less & 112 & 17 & 95 & \\
\hline $2.0-4.0$ & 47 & 17 & 30 & \\
\hline Greater than 4.0 & 31 & 20 & 11 & \\
\hline unknown & 65 & 23 & 42 & $<0.001^{*}$ \\
\hline Mean \pm SD & $2.48 \pm 2.38$ & $4.01 \pm 3.38$ & $1.88 \pm 1.45$ & $<0.001^{\text {§ }}$ \\
\hline \multicolumn{5}{|c|}{$\%$ positive biopsy core } \\
\hline Less than 34 & 158 & 38 & 120 & \\
\hline $34-50$ & 22 & 6 & 16 & \\
\hline 50 or greater & 66 & 32 & 34 & \\
\hline unknown & 9 & 1 & 8 & $0.001^{*}$ \\
\hline
\end{tabular}

or less showed a significantly lower biochemical recurrencefree rate than those with $2.1-4.0 \mathrm{~mL}$ and greater than $4.0 \mathrm{~mL}$, respectively $(P=0.0008$, and $P<0.0001)$. Patients with 2.1-4.0 $\mathrm{mL}$ also showed a significantly lower biochemical recurrence rate than those with greater than $4.0 \mathrm{~mL}(P=$ 0.0109).

\subsection{Biochemical Recurrence-Free Rate of Postoperative Patho-} logical Parameters. Regarding the pathological parameters obtained at surgery, the pathological Gleason score and the pathological T stage were statistically higher in patients who showed biochemical recurrence, and the number of patients who showed EPE, PSM, or SVI was also statistically greater than those without biochemical recurrence.

The estimated 5-year biochemical recurrence-free rates of pathological T0, T2, T3a, T3b, and T4 were $80.0 \%, 76.1 \%$, $57.0 \%, 0 \%$, and $0 \%$, respectively. A log rank test showed significant differences among the pathological $\mathrm{T}$ stages.

Regarding EPE, the estimated 5-year biochemical recurrence-free rates of patients with positive and negative EPE were $72.8 \%$ and $53.2 \%$, respectively $(P=0.0167)$. Regarding SVI, the estimated 5-year biochemical recurrence-free rates of patients with positive and negative SVI were $71.0 \%$ and $0 \%$, respectively $(P<0.0001)$. Regarding the surgical margin status, the estimated 5-year biochemical recurrence-free rates of patients with a positive and a negative surgical margin were $76.0 \%$ and $47.6 \%$, respectively $(P<0.0001)$.

3.3. Multivariate Analysis Using Preoperative and Postoperative Clinicopathological Parameters. Regarding the preoperative clinicopathological parameters, biopsy Gleason score, clinical stage, PSA at biopsy, percent positive cores, and calculated cancer volume were independent predictors of biochemical recurrence in univariate analysis. Multivariate analysis using the Cox proportional hazards model showed that the calculated cancer volume was the independent predictor $(P<0.05)$ (Table 3$)$.

Regarding postoperative pathological parameters, surgical Gleason score, EPE, SVI, and PSM were independent predictors of biochemical recurrence in univariate analysis. 
TABLe 2: Postoperative clinicopathological parameters.

\begin{tabular}{|c|c|c|c|c|}
\hline & $\begin{array}{l}\text { All patients } \\
(n=255)\end{array}$ & $\begin{array}{l}\text { Biochem. recur. }(+) \\
\quad(n=77)\end{array}$ & $\begin{array}{c}\text { Biochem. recur. }(-) \\
\quad(n=178)\end{array}$ & $P$ value \\
\hline \multicolumn{5}{|c|}{ Surgical Gleason score } \\
\hline$\leqq 6$ & 122 & 30 & 92 & \\
\hline 7 & 89 & 29 & 60 & \\
\hline $8-10$ & 23 & 13 & 10 & \\
\hline Unknown & 21 & 5 & 16 & $0.009^{*}$ \\
\hline \multicolumn{5}{|c|}{ Pathological stage } \\
\hline T0 & 5 & 1 & 4 & \\
\hline $\mathrm{T} 2$ & 170 & 40 & 130 & \\
\hline T3a & 68 & 25 & 43 & \\
\hline $\mathrm{T} 3 \mathrm{~b}$ & 10 & 9 & 1 & \\
\hline $\mathrm{T} 4$ & 2 & 2 & 0 & $0.001^{*}$ \\
\hline \multicolumn{5}{|l|}{$\mathrm{EPE}$} \\
\hline Positive & 74 & 30 & 44 & \\
\hline Negative & 181 & 47 & 134 & $0.017^{*}$ \\
\hline \multicolumn{5}{|c|}{ Surgical margin } \\
\hline Positive & 64 & 29 & 35 & \\
\hline Negative & 164 & 35 & 129 & \\
\hline Unknown & 33 & 13 & 20 & $<0.001^{*}$ \\
\hline \multicolumn{5}{|l|}{ SVI } \\
\hline Positive & 12 & 11 & 1 & \\
\hline Negative & 243 & 66 & 177 & $<0.001^{*}$ \\
\hline
\end{tabular}

Biochem. recur.: biochemical recurrence, EPE: extraprostatic extension, SVI: seminal vesicle involvement.

* Chi-square test and ${ }^{\S}$ Mann Whitney $U$ test.

Multivariate analysis using the Cox proportional hazards model showed that SVI and PSM were the independent predictors (SVI; $P<0.001$, PSM; $P=0.049$ ) (Table 4).

We conducted multivariate analysis using calculated cancer volumes, SVI and PSM, which were significant predictors in multivariate analysis of both preoperative and postoperative parameters. Consequently, SVI and PSM lost their significance and calculated cancer volume was the independent predictor $(P<0.01)$ (Table 5).

\section{Discussion}

Many investigators have tried to determine independent predictors of biochemical recurrence in patients who had undergone radical prostatectomy [8-20]. Among the preoperative clinicopathological parameters, PSA at biopsy, biopsy Gleason score, clinical stage, percent biopsy core, risk classification, and calculated tumor volume were reported as independent predictors, while pathological stage, EPE, SVI, PSM, tumor volume, and surgical Gleason score were reported as independent predictors of biochemical recurrence among the postoperative pathological parameters.

Regarding the predictive potency of tumor volume in biochemical recurrence after radical prostatectomy, some investigators take an affirmative stance $[17,21]$, while others postulate a dismissive view [22-25]. Taking the affirmative stance, the prediction of the tumor volume of prostate cancer leads to the prediction of biochemical recurrence after radical prostatectomy. This prediction is not only useful in patients who undergo radical prostatectomy, but also those who receive definitive radiation therapy (e.g., IMRT, highdose-rate and low-dose-rate brachytherapy). An attempt to calculate the tumor volume of prostate cancer has been reported by several investigators [17-21].

In the present study, we calculated the tumor volume according to the equation reported by D'Amico et al. [7]. Using the preoperative parameters, tumor volume had an independent potency of prediction of biochemical recurrence in multivariate analysis. Using the postoperative parameters, SVI and PSM remained as independent predictors. Using these three independent preoperative and postoperative parameters, only tumor volume remained significant. SVI and PSM were marginal predictive values $(P=0.073$, and 0.058 , resp.). On the other hand, Chan and Stamey verified the equation to calculate tumor volume reported by D'Amico, and they reported that there was a significant correlation between the calculated cancer volume and the actual total cancer volume $(r=0.537 ; P<0.0001)$ [22]. However, they concluded that PSA was a much stronger predictor of cancer volume than calculated prostate cancer volume.

Our present study has several limitations, namely, the number of patients is small $(n=255)$, the mean followup period is short (53 months), and we have not calculated the tumor volume by using radical prostatectomy specimens yet. The correlation between calculated tumor volume and true tumor volume in our patients is unknown. However, the calculated tumor volume indeed had an independent 
TABLE 3: Univariate and multivariate analysis in preoperative clinicopathological parameters.

\begin{tabular}{|c|c|c|c|c|c|c|}
\hline \multirow{2}{*}{ Parameter } & \multicolumn{3}{|c|}{ Univariate } & \multicolumn{3}{|c|}{ Multivariates } \\
\hline & Hazard ratio & 95\% C.I. & $P$ value & Hazard ratio & 95\% C.I. & $P$ value \\
\hline Age (continuous) & 0.984 & $0.944-1.027$ & 0.462 & & & N.A. \\
\hline \multicolumn{7}{|l|}{$\begin{array}{l}\text { Biopsy Gleason } \\
\text { score }\end{array}$} \\
\hline 6 or less & 1 & & & 1 & & \\
\hline 7 & 1.269 & $0.663-2.430$ & 0.472 & 0.658 & $0.281-1.543$ & 0.336 \\
\hline $8-10$ & 4.103 & $2.199-7.656$ & $<0.001$ & 0.925 & $0.312-2.739$ & 0.888 \\
\hline \multicolumn{7}{|l|}{ Clinical stage } \\
\hline $\mathrm{T} 1$ & 1 & & & 1 & & \\
\hline $\mathrm{T} 2$ & 1.719 & $1.048-2.819$ & 0.032 & 1.191 & $0.652-2.177$ & 0.567 \\
\hline $\mathrm{T} 3$ & 4.298 & $0.583-31.654$ & 0.152 & 4.037 & $0.507-32.121$ & 0.187 \\
\hline \multicolumn{7}{|l|}{$\begin{array}{l}\text { PSA at biopsy } \\
(\mathrm{ng} / \mathrm{mL})\end{array}$} \\
\hline 10 or less & 1 & & & 1 & & \\
\hline $10-20.0$ & 1.543 & $0.892-2.668$ & 0.121 & 0.961 & $0.398-2.324$ & 0.930 \\
\hline Greater than 20 & 4.555 & $2.314-8.965$ & $<0.001$ & 0.892 & $0.258-3.089$ & 0.857 \\
\hline \multicolumn{7}{|l|}{$\%$ positive cores } \\
\hline Less than 34 & 1 & & & 1 & & \\
\hline $34-50$ & 1.139 & $0.444-2.920$ & 0.787 & 1 & $0.333-2.999$ & 1.000 \\
\hline 50 or greater & 2.340 & $1.384-3.956$ & 0.002 & 1.807 & $0.949-3.444$ & 0.072 \\
\hline \multicolumn{7}{|l|}{$\begin{array}{l}\text { Calculated cancer } \\
\text { volume }(\mathrm{mL})\end{array}$} \\
\hline 2.0 or less & 1 & & & 1 & & \\
\hline $2.0-4.0$ & 2.716 & $1.323-5.577$ & 0.006 & 3.022 & $1.144-7.981$ & 0.026 \\
\hline Greater than 4.0 & 7.116 & $3.595-14.085$ & $<0.001$ & 6.962 & $1.755-27.624$ & 0.006 \\
\hline
\end{tabular}

N.A.: not available. C.I: confidence interval.

TABLE 4: Univariate and multivariate analysis in postoperative clinicopathological parameters.

\begin{tabular}{|c|c|c|c|c|c|c|}
\hline \multirow{2}{*}{ Parameter } & \multicolumn{3}{|c|}{ Univariate } & \multicolumn{3}{|c|}{ Multivariates } \\
\hline & Hazard ratio & 95\% C.I. & $P$ value & Hazard ratio & 95\% C.I. & $P$ value \\
\hline \multicolumn{7}{|c|}{$\begin{array}{l}\text { Surgical Gleason } \\
\text { score }\end{array}$} \\
\hline 6 or less & 1 & & & 1 & & \\
\hline 7 & 1.329 & $0.748-2.360$ & 0.332 & 0.884 & $0.458-1.706$ & 0.713 \\
\hline $8-10$ & 3.345 & $1.716-6.522$ & $<0.001$ & 1.858 & $0.840-4.113$ & 0.126 \\
\hline \multicolumn{7}{|l|}{$\overline{\mathrm{EPE}}$} \\
\hline Negative & 1 & & & 1 & & \\
\hline Positive & 2.026 & $1.232-3.331$ & 0.005 & 1.337 & $0.735-2.431$ & 0.342 \\
\hline \multicolumn{7}{|l|}{$\begin{array}{l}\text { SVI } \\
\end{array}$} \\
\hline Negative & 1 & & & 1 & & \\
\hline Positive & 8.425 & $4.219-16.825$ & $<0.001$ & 4.615 & $1.996-10.672$ & $<0.001$ \\
\hline \multicolumn{7}{|c|}{ Surgical margin } \\
\hline Negative & 1 & & & 1 & & \\
\hline Positive & 2.943 & $1.704-5.080$ & $<0.001$ & 1.902 & $1.001-3.614$ & 0.049 \\
\hline
\end{tabular}

EPE: extraprostatic extentions, SVI: seminal vesicle involvement, C.I.: confidence interval. 
TABLE 5: Univariate and multivariate analysis in both preoperative and postoperative clinicopathological parameters.

\begin{tabular}{|c|c|c|c|c|c|c|}
\hline \multirow[b]{2}{*}{ Parameter } & \multicolumn{3}{|c|}{ Univariate } & \multicolumn{3}{|c|}{ Multivariates } \\
\hline & Hazard ratio & 95\% C.I. & $P$ value & Hazard ratio & 95\% C.I. & $P$ value \\
\hline \multicolumn{7}{|l|}{ SVI } \\
\hline Negative & 1 & & & 1 & & \\
\hline positive & 8.425 & $4.219-16.825$ & $<0.001$ & 2.460 & $0.919-6.580$ & 0.073 \\
\hline \multicolumn{7}{|l|}{ Surgical marrgin } \\
\hline Negative & 1 & & & 1 & & \\
\hline positive & 2.943 & $1.704-5.080$ & $<0.001$ & 2.057 & $0.975-4.339$ & 0.058 \\
\hline \multicolumn{7}{|l|}{$\begin{array}{l}\text { Calculated cancer } \\
\text { volume }(\mathrm{mL})\end{array}$} \\
\hline 2.0 or less & 1 & & & 1 & & \\
\hline $2.1-4.0$ & 2.716 & $1.323-5.577$ & 0.006 & 3.191 & $1.397-7.291$ & 0.006 \\
\hline Greater than 4.0 & 7.116 & $3.595-14.058$ & $<0.001$ & 4.498 & $1.749-11.564$ & 0.002 \\
\hline
\end{tabular}

SVI: seminal vesicle involvement, C.I: confidence Interval.

predictive potency for biochemical recurrence after radical prostatectomy in multivariate analyses not only among preoperative parameters, but also pre- and postoperative parameters.

Since the progress in definitive radiation therapy, pretreatment predictive parameters of oncological outcomes after definitive therapy in patients with localized and locally advanced prostate cancer are expected.

\section{Conclusion}

The calculated tumor volume by preoperative parameters can be an independent predictor of recurrence for patients and will experience biochemical recurrence.

\section{Conflict of Interests}

The authors declare that they have no conflict of interests.

\section{References}

[1] P. C. Walsh, "Anatomic radical prostatectomy: evolution of the surgical technique," Journal of Urology, vol. 160, no. 6, pp. 2418-2424, 1998.

[2] M. Menon, A. Shrivastava, S. Kaul et al., "Vattikuti institute prostatectomy: contemporary technique and analysis of results," European Urology, vol. 51, no. 3, pp. 648-658, 2007.

[3] A. T. Savera, S. Kaul, K. Badani, A. T. Stark, N. L. Shah, and M. Menon, "Robotic radical prostatectomy with the "Veil of Aphrodite" technique: histologic evidence of enhanced nerve sparing," European Urology, vol. 49, no. 6, pp. 1065-1073, 2006.

[4] N. Tanaka, K. Fujimoto, A. Hirayama, T. Yoneda, K. Yoshida, and Y. Hirao, "Trends of the primary therapy for patients with prostate cancer in nara uro-oncological research group (NUORG): a comparison between the CaPSURE data and the NUORG data," Japanese Journal of Clinical Oncology, vol. 40, no. 6, pp. 588-592, 2010.

[5] C. Wittekind, C. C. Compton, F. L. Greene, and L. H. Sobin, "TNM residual tumor classification revisited," Cancer, vol. 94, no. 9, pp. 2511-2516, 2002.
[6] A. V. D’Amico, R. Whittington, S. B. Malkowicz et al., "Biochemical outcome after radical prostatectomy, external beam radiation therapy, or interstitial radiation therapy for clinically localized prostate cancer," The Journal of the American Medical Association, vol. 280, no. 11, pp. 969-974, 1998.

[7] A. V. D’Amico, H. Chang, E. Holupka et al., "Calculated prostate cancer volume: the optimal predictor of actual cancer volume and pathologic stage," Urology, vol. 49, no. 3, pp. 385391, 1997.

[8] M. W. Kattan, J. A. Eastham, A. M. F. Stapleton, T. M. Wheeler, and P. T. Scardino, "A preoperative nomogram for disease recurrence following radical prostatectomy for prostate cancer," Journal of the National Cancer Institute, vol. 90, no. 10, pp. 766-771, 1998.

[9] A. W. Partin, L. A. Mangold, D. M. Lamm, P. C. Walsh, J. I. Epstein, and J. D. Pearson, "Contemporary update of prostate cancer staging nomograms (Partin Tables) for the new millennium," Urology, vol. 58, no. 6, pp. 843-848, 2001.

[10] M. R. Cooperberg, D. J. Pasta, E. P. Elkin et al., "The University of California, San Francisco cancer of the prostate risk assessment score: a straightforward and reliable preoperative predictor of disease recurrence after radical prostatectomy," Journal of Urology, vol. 173, no. 6, pp. 1938-1942, 2005.

[11] K. H. Zhao, D. J. Hernandez, M. Han, E. B. Humphreys, L. A. Mangold, and A. W. Partin, "External validation of University of California, San Francisco, cancer of the prostate risk assessment score," Urology, vol. 72, no. 2, pp. 396-400, 2008.

[12] G. W. Hull, F. Rabbani, F. Abbas, T. M. Wheeler, M. W. Kattan, and P. T. Scardino, "Cancer control with radical prostatectomy alone in 1,000 consecutive patients," Journal of Urology, vol. 167, no. 2, pp. 528-534, 2002.

[13] K. A. Roehl, M. Han, C. G. Ramos, J. A. V. Antenor, and W. J. Catalona, "Cancer progression and survival rates following anatomical radical retropubic prostatectomy in 3,478 consecutive patients: long-term results," Journal of Urology, vol. 172, no. 3, pp. 910-914, 2004.

[14] S. J. Freedland, W. J. Aronson, M. K. Terris et al., "Percent of prostate needle biopsy cores with cancer is a significant independent predictor of prostate specific antigen recurrence following radical prostatectomy: results from the SEARCH database," Journal of Urology, vol. 169, no. 6, pp. 2136-2141, 2003. 
[15] A. Briganti, F. K. Chun, G. C. Hutterer et al., "Systematic assessment of the ability of the number and percentage of positive biopsy cores to predict pathologic stage and biochemical recurrence after radical prostatectomy," European Urology, vol. 52, no. 3, pp. 733-745, 2007.

[16] S. Suekane, M. Noguchi, O. Nakashima, S. Yamada, M. Kojiro, and K. Matsuoka, "Percentages of positive cores, cancer length and Gleason grade 4/5 cancer in systematic sextant biopsy are all predictive of adverse pathology and biochemical failure after radical prostatectomy," International Journal of Urology, vol. 14, no. 8, pp. 713-718, 2007.

[17] A. F. Olumi, J. P. Richie, D. J. Schultz, and A. V. D'Amico, "Calculated volume of prostate cancer identifies patients with clinical stage T1C disease at high risk of biochemical recurrence after radical prostatectomy: a preliminary study," Urology, vol. 56, no. 2, pp. 273-277, 2000.

[18] F. K. Chun, A. Briganti, C. Jeldres et al., "Tumour volume and high grade tumour volume are the best predictors of pathologic stage and biochemical recurrence after radical prostatectomy," European Journal of Cancer, vol. 43, no. 3, pp. 536-543, 2007.

[19] M. Ates, D. Teber, A. S. Gözen et al., "Do tumor volume, tumor volume ratio, type of nerve sparing and surgical experience affect prostate specific antigen recurrence after laparoscopic radical prostatectomy? A matched pair analysis," Journal of Urology, vol. 177, no. 5, pp. 1771-1776, 2007.

[20] B. A. Nelson, S. B. Shappell, S. S. Chang et al., "Tumour volume is an independent predictor of prostate-specific antigen recurrence in patients undergoing radical prostatectomy for clinically localized prostate cancer," BJU International, vol. 97, no. 6, pp. 1169-1172, 2006.

[21] M. Alschibaja, M. Wegner, J. Massmann, A. Funk, R. Hartung, and R. Paul, "Prostate cancer volume-can it be predicted preoperatively?" Urologia Internationalis, vol. 75, no. 4, pp. 354-359, 2005.

[22] L. W. Chan and T. A. Stamey, "Calculating prostate cancer volume preoperatively: the d'Amico equation and some other observations," Journal of Urology, vol. 159, no. 6, pp. 19982003, 1998.

[23] L. Salomon, O. Levrel, A. G. Anastasiadis et al., "Prognostic significance of tumor volume after radical prostatectomy: a multivariate analysis of pathological prognostic factors," European Urology, vol. 43, no. 1, pp. 39-44, 2003.

[24] E. Kikuchi, P. T. Scardino, T. M. Wheeler, K. M. Slawin, and M. Ohori, "Is tumor volume an independent prognostic factor in clinically localized prostate cancer?" Journal of Urology, vol. 172, no. 2, pp. 508-511, 2004.

[25] M. M. Merrill, B. R. Lane, A. M. Reuther, M. Zhou, C. MagiGalluzzi, and E. A. Klein, "Tumor volume does not predict for biochemical recurrence after radical prostatectomy in patients with surgical gleason score 6 or less prostate cancer," Urology, vol. 70, no. 2, pp. 294-298, 2007. 


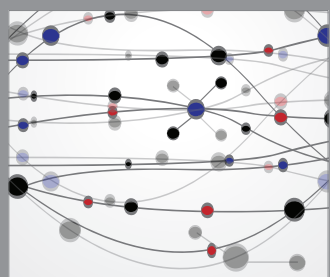

The Scientific World Journal
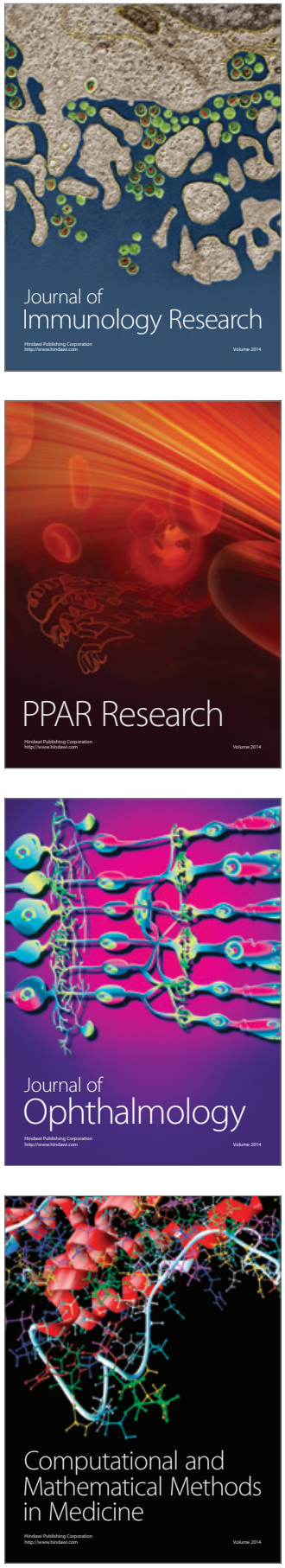

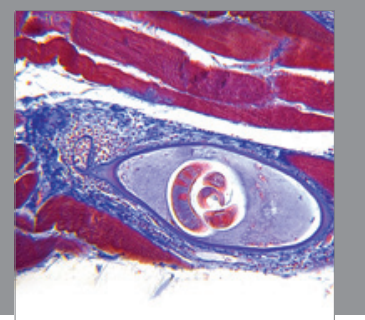

Gastroenterology

Research and Practice
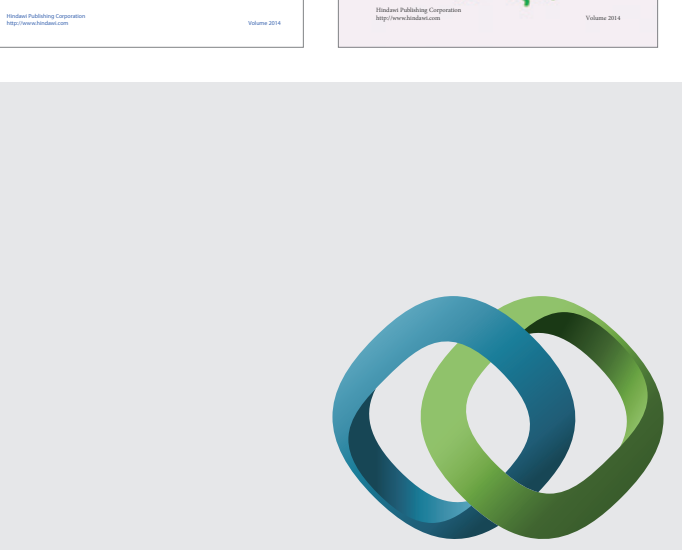

\section{Hindawi}

Submit your manuscripts at

http://www.hindawi.com
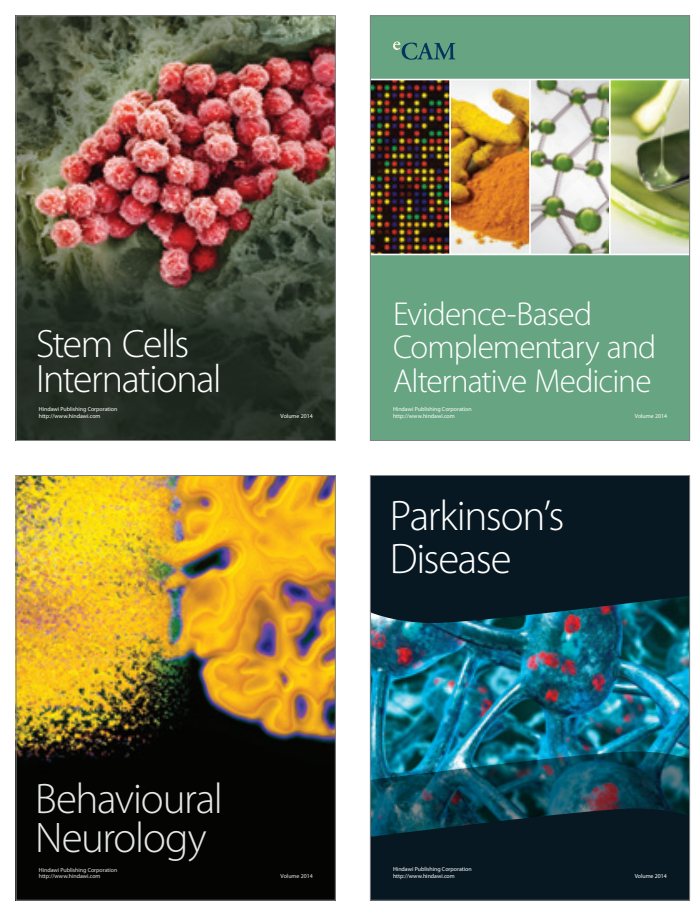

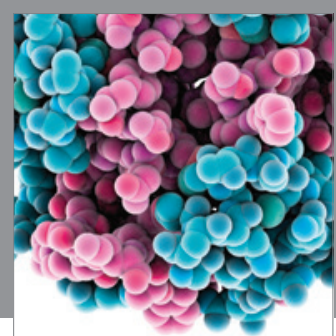

Journal of
Diabetes Research

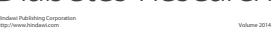

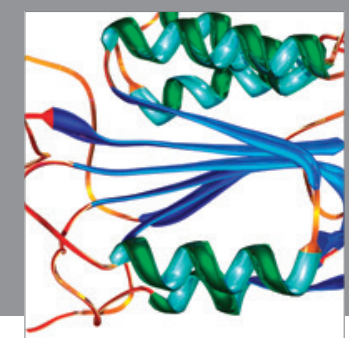

Disease Markers
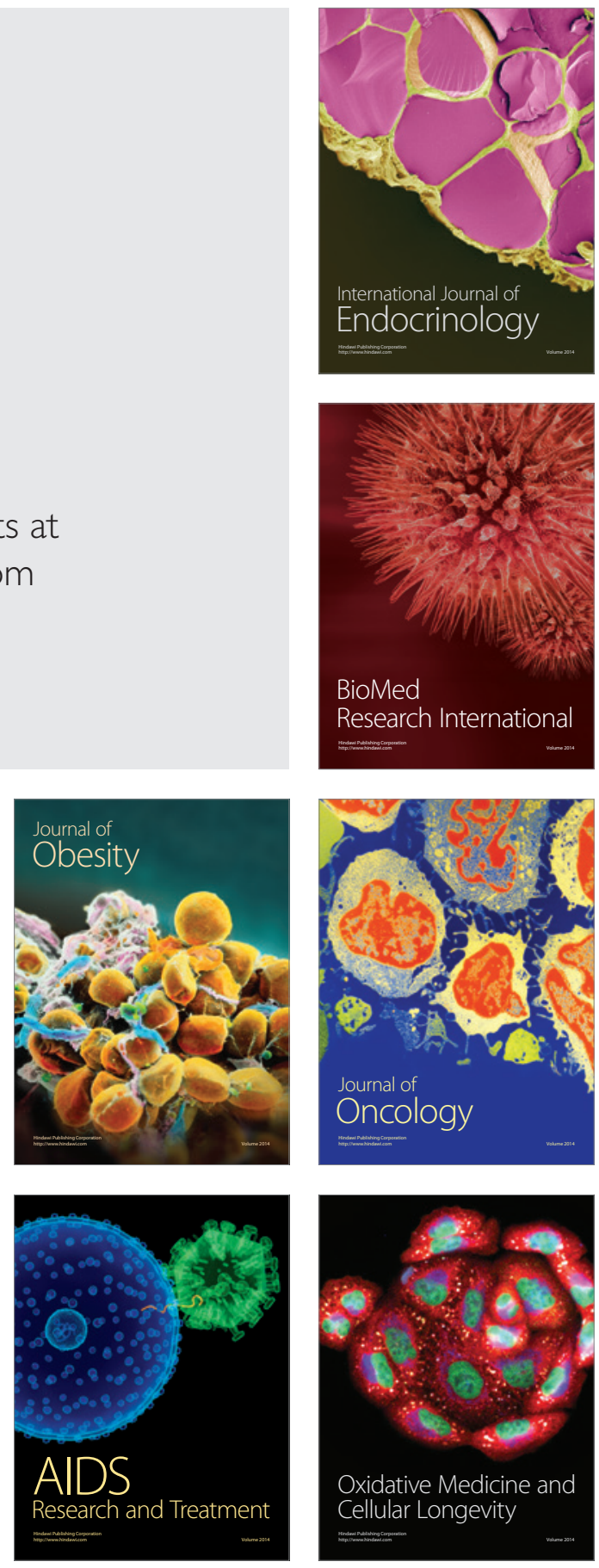